\title{
From the patient's point of view: medical ethics and the moral imagination
}

\author{
Carl Elliott and Britt Elliott University of Otago Bioethics Research Centre, New Zealand \\ and Czechoslavakia Academy of Sciences, respectively
}

\section{Authors' abstract}

This paper concerns the difficulties of imagining the subjective point of view of another human being, and the relevance of these difficulties to medical decisions. It explores especially the difficulties of imagining the experience of the mentally impaired, and examines several standards for decision-making: the "prior expressed wishes standard', the 'substituted judgement standard', and the 'best interests standard'.

Fania Pascal writes that Ludwig Wittgenstein, whom she was teaching Russian in Cambridge, once called on her when she was recovering in the hospital after having her tonsils removed. When Wittgenstein asked how she felt, Pascal responded that she felt just like a dog who had been run over by a truck. Wittgenstein, says Pascal, seemed to become rather disgusted at this comparison, and gave her the terse reply: 'You don't know what a dog feels like' (1).

Setting aside questions of bedside manner, Wittgenstein was making an important point, one which is probably more familiar to anthropologists than to doctors. Anthropology requires us to try to understand cultures which are vastly different from our own, and to do this requires that we try to establish some sort of psychological identification with the members of that culture, to see things 'from the native's point of view' (2). Medicine also requires this sort of identification, this leap of the moral imagination; doctors are called upon to make decisions for their patients, whose illness may have transformed their existence dramatically, and to understand the feelings and values of an ill person requires the doctor to try to assume, like the anthropologist, a point of view other than his own. But as Wittgenstein points out, this effort is one which, at least in some sense, is destined to fail. In medicine, as in anthropology, the imagination has definite and often overlooked limits.

\section{The imagination and the self}

That doctors must make these sort of imaginative leaps

\section{Key words}

Ethics; imagination; substituted judgement; mental impairment; advance directives; interests. should not be controversial. Without them it would be impossible to feel the emotions tied to moral judgement, the passions to which Hume thought reason was slave. My sympathy for the man who will soon have his leg amputated arises from my imagination of what it would be like if I were to lose a leg. If a doctor is to establish solidarity with his patients he must imagine what it would be like, for example, to face a life tied to a dialysis machine, to suffer the loss of a child, to hallucinate, or to lose one's sight. This idea is not unfamiliar to moral philosophy; it was, in fact, central to the philosophy of Adam Smith, who wrote at the beginning of the Theory of Moral Sentiments:

'As we have no experience of what other men feel, we can form no idea of the manner in which they are affected, but by conceiving what we ourselves should feel in the like situation. Though our brother is on the rack, as long as we ourselves are at our ease, our senses will never inform us of what he suffers. They never did, and never can, carry us beyond our own person, and it is by the imagination only that we can form any conception of what are his sensations' (3).

Nonetheless, the imagination has its boundaries. Clearly it is much easier for me to imagine what it would be like for $m e$ to undergo a given experience than it is for me to imagine what undergoing that experience is like for another person. That sort of imaginative leap would require me to imagine what it is like to share another person's particular, subjective point of view, to imagine what it is like to $b e$ another person - and this is another matter entirely.

To imagine what it would be like to be another person requires me to imagine the logically impossible: what would I be like if I were no longer I? The question is clearly absurd; nevertheless, it is tempting to suppose that this imaginative leap can be accomplished. For example, it is sometimes assumed that one can logically, if not actually, transpose one's identity into another being. Consider the protagonist of Kafka's Metamorphosis. When the novel begins, Gregor Samsa has awoken to find himself transformed into a gigantic insect. Every physical attribute of Samsa the man has vanished: he has many thin, spindly legs instead of four substantial ones, he has a shell on his 
back; he has apparently even lost his original language, which has been reduced to chirps and peeps. Yet despite all these changes, the insect is still Samsa. Samsa's 'self' remains intact.

Kafka's story shows the sort of mistake that we are likely to make when we make these sorts of imaginative leaps. We are tempted to believe that it is logically possible for one to transpose one's identity into another being; to ask oneself: 'What if I were someone (or something) else?' But such a question assumes a logical contradiction. One might as well ask: 'What would a cat be like, if it were a dog?' or 'What would a square be like, if it were a circle'?

One danger of failing to recognise these limits to the imagination lies in the temptation to judge the quality of the experience of a person or being whose experience is radically different from one's own. Usually, the judgements that result are not particularly favourable. In a famous rhetorical flourish, John Stuart Mill seems to have attempted this sort of long imaginative leap when he wrote:

'It is better to be a human being dissatisfied than a pig satisfied; better to be a Socrates dissatisfied than a fool satisfied. And if the fool, or the pig, are of a different opinion, it is because they only know their own side of the question. The other party to the question knows both sides' (4).

Assume for a moment that Mill (unlike Fania Pascal) intended his comparison to be taken literally. When Mill says that it is better to be a human being dissatisfied than a pig satisfied, the question presents itself: better for whom? We certainly cannot meaningfully say that it is better for the human that he is not a pig, or worse for the pig that he is not a human. The question makes the tacit assumption that there exists a subject which can experience what it is like to be a human, what it is like to be a pig, and then compare the two. But the experience of being a pig is available only to pigs, and that of being human only to humans. The reason why Mill cannot say that it is better to be a human being than a pig is that neither party to the question knows, or logically can know, both sides.

Now all this is not simply to say that it is logically impossible to imagine the experiences of another being. It may well be impossible, but that does not matter; my experience is usually close enough to yours so that even if it is logically impossible for me to imagine it, I can make do with a pretty close approximation. Indeed, the unsaid assumption underlying much of imaginative literature, not to mention anthropology, is that there are enough core similarities between various kinds of human experience to ensure we have something to learn from the experiences of others, and that we can, with some help, imagine what many varieties of human experiences are like.

Our point, rather, is that one's imagination is normally an extrapolation of one's own experience, and the less similar one's own experience is to that of another being, the more difficult that being's experience will be for one to imagine. This point is especially important for medicine, which often requires one to imagine experiences which are vastly different from one's own - for instance, the experiences of the permanently mentally impaired.

\section{Prior expressed wishes of the permanently mentally impaired}

Doctors and patients' families must often make medical decisions for individuals whose mental abilities are so limited that they are permanently unable to make decisions for themselves. For mentally impaired patients who at one time had normal mental abilities, such as the demented elderly or patients with Alzheimer's Disease, doctors routinely make decisions on the basis of an individual patient's prior expressed wishes about medical treatment. Doctors encourage mentally sound patients to think about and articulate what sort of medical treatment they would choose to undergo or reject should they become mentally impaired, and if patients do indeed reach such a state, doctors decide on treatment based on the patients' wishes.

The problem with this initially plausible 'expressed wishes' standard is that it begins to seem shaky when we examine the foundations on which it is built. This standard assumes that the person who is mentally impaired is essentially the 'same person' as the one who expressed his or her wishes about treatment. This is what doctors assume when they ask families about patients' prior wishes, and this is what patients assume when they express such wishes: that when a patient becomes mentally impaired, he will be the same person as he was when he was mentally normal. The 'sameness' of the person expressing the wishes and the person being treated is the assumption upon which this standard rests.

But in many ways - and probably the most important ways - a person who has become permanently mentally deficient is not the same person as he was before. The patient often has little memory of his previous life; his personality has changed; his intellect has deteriorated; and he has different needs, concerns, beliefs, and desires than before. Gone is much of the psychological continuity which is often thought to be necessary for personal identity. (In fact, families of such patients often say that the patient is 'not the same person'.) Of course, whether we should think of the severely impaired patient as different from or the same as his earlier self raises controverted problems for the question of personal identity, and here is not the place for those problems to be discussed. The point for our purposes is that this break between the mentally normal and the mentally impaired self is one alien to the experience of most human beings, and that these changes - in personality, memory, intellectual abilities, needs, desires and so on - mean that the mentally impaired person is in important ways 
different from the person he once was.

Nonetheless, we often act as if such patients are the same persons as before, and as if we would ourselves remain the same persons even if our mental functions should change radically. Georg Christof Lichtenberg wrote: 'I have a knife that is without a blade, and the handle is missing'. And we think: I have a self that is without a body, and the mind is missing. We are seduced into thinking of the self as a subject which, even when stripped of all its constituents, still remains, like the Cheshire cat's smile.

The extent to which a person changes when her mental abilities deteriorate obstructs the abilities of doctors and families to make decisions for her in two ways. First, if the mentally deficient person is importantly different from the mentally normal one, then the person who expressed her wishes about treatment is importantly different from the one who is being treated. And this difference seems to undermine the authority of the patient's wishes.

Second, if a person whose mental capacities diminish greatly is not the same person, then for that person to express his wishes about treatment in such circumstances requires him to imagine what it would be like to be in those circumstances. And of course, to the extent that a person is no longer the same person when he becomes severely mentally impaired, the problem of imagining what it would be like to be mentally impaired is like the problem of imagining what it would be like to be another person: to do it requires one to imagine the logically impossible.

Do these problems mean that we should simply forget about mentally impaired patients' previously expressed wishes, and forget about making our own wishes about such eventualities known? Probably not. One might well argue that even if a person's mental abilities have deteriorated so much as to make him a different person, we should still abide by his wishes just as we often feel obligated, in some cases, to abide by a dead person's wishes (think of a will, or a death bed promise). And even if there are constraints on our abilities to imagine what it is like to be mentally impaired, we may still have good reason to make our wishes known about such eventualities. For example, a person might want to make plans which would spare his family the hardship of having to take care of a severely mentally impaired person. Rather, these problems should be taken as a reminder, first, that the prior wishes of the mentally impaired ought not to be taken to be as morally authoritative as the wishes of a competent paticnt, and second, that such wishes may well be based on beliefs which are false or tenuous that is, mistaken beliefs about what it is like to be severely mentally impaired.

\section{Substituted judgement for the mentally impaired}

In many instances a mentally impaired patient either has never been mentally sound, or even if he was at one time mentally sound, never expressed any preferences about what sort of medical treatment he would choose if he became permanently mentally impaired. In such cases doctors often turn to the standard of substituted judgement, which asks: What would this patient choose if he were able?

The problems with such an approach should be clear. If a mentally impaired person were able to choose, she would not be mentally impaired. A necessary constituent of what it means to be this mentally impaired is to be unable to make such decisions; to imagine that a mentally impaired person is able to choose is in one important way to imagine that she is a different person.

The difficulties with substituted judgement for the mentally impaired are illustrated in the well known US court case, Superintendent of Belchertown State School v Foseph Saikewicz (5), in which the Massachusetts Supreme Judicial Court decided that chemotherapy could legitimately be withheld from Mr Saikewicz, a profoundly retarded 67-year-old man with acute myeloblastic monocytic leukaemia. The court appealed to the standard of substituted judgement in order to determine whether Mr Saikewicz, a man with an IQ of 10 , would choose to undergo a painful treatment which probably would only prolong his life for a short time. The court realised that the majority of rational, competent individuals would indeed choose to undergo the painful treatment, but it argued that Saikewicz's condition made circumstances such that the decisions of competent individuals could not be transposed onto him. Because Mr Saikewicz would be unable to understand that the pain he was undergoing would be for long-term gain, the court contended that his situation must be treated differently from that of a person who was capable of such understanding. For this reason the court decided that the treatment should be withheld.

Saikewicz illustrates the sort of imaginative backflips that one must undergo in trying to make decisions based on substituted judgement for persons of severely limited intelligence. The court's reasoning seems to have gone something like the following. A person of severely limited intelligence cannot make decisions for himself. So we need to make decisions for him based on what he would choose if he could. But being able to choose entails having high intelligence. And persons of high intelligence have different concerns, values and interests than persons of very low intelligence, and therefore would make different decisions than persons of very low intelligence. Thus it seems that the court cannot base its decision on what a person of very low intelligence would choose because a person of very low intelligence necessarily cannot choose; and it cannot base its decision on what a person of high intelligence would choose, because a person of high intelligence would, of course, make his choice based on the concerns, values and interests of a person of high intelligence. So the court attempted a decision based on what a person of high intelligence would choose if he had very low intelligence. On these grounds, 
Saikewicz's treatment was withheld.

It may well be that the decision to withhold treatment was the best choice for Joseph Saikewicz, given his circumstances. What is unnecessarily circuitous is the route by which the court arrived at that decision. It seems clear that the court was attempting to make a decision based on Mr Saikewicz's best interests - a standard which has problems of its own, but which was probably the best standard for this case. But a best interests standard needs to be made explicit and defended on its own grounds, not disguised as substituted judgement.

\section{Best interests and quality of life}

A third standard which is sometimes invoked to justify medical decisions for the mentally impaired is the standard of 'best interests'. That is, doctors and caretakers should act in what they judge to be the best interests of the patient. This standard appears to be the best one for such decisions, because it does not require one to imagine the logical contradictions which may be entailed in imagining oneself as mentally impaired, or imagining a mentally impaired individual to be mentally sound.

Nonetheless, the best interests standard is not without its difficulties. Any notion of a patient's interests will be incomplete unless it takes account of that patient's subjective experience, and because we are usually unable to communicate to much extent with the severely mentally impaired, their subjective experience is in large degree available only to them. Thus any judgement of a patient's interests will be based on the decision-maker's impression of that patient's experience, and these impressions may well be inaccurate.

In forming such impressions of a patient's subjective experience, decision-makers can fall prey to two sorts of mistakes. The first is the sort to which we have alluded before - assuming that one can imagine with accuracy what it is like to be in that patient's situation. One particular danger in making decisions for the mentally impaired is the assumption that a mental impairment diminishes the quality of an individual's life. It is tempting to reason thus: the quality of my life would be lessened if I were mentally impaired, so it seems likely that this individual's quality of life is less than it would be if he were mentally normal. But as we have seen, we have reason to doubt whether a person can imagine with accuracy what it is like to be mentally impaired. And so this sort of reasoning does nothing to further the argument that mental impairment diminishes an individual's quality of life.

A second problem with forming an impression of another person's subjective experience relates to the core of the notion of subjectivity: every subjective experience is different from every other subjective experience. Up to this point we have limited our discussion to what is common to subjective experiences of a particular type, the points of convergence of the experiences of all mentally impaired persons. But when we make a decision for a particular mentally impaired person, we are interested not in a type of subjective experience; rather, we are interested in the subjective experience of a particular individual. That is, even if I could be certain that most demented elderly persons with aspiration pneumonia find their existence miserable, this knowledge would be of only marginal help, because what I must know is what it is like for this elderly demented man with aspiration pneumonia.

This problem can be especially dangerous when one must make quality-of-life decisions for mentally deficient persons with physical handicaps. Many times a decision-maker must decide whether an individual's quality of life is such that it would be morally better to prolong that life or allow it to end. In these cases, she may reason that since most persons who have such physical handicaps and are able to communicate find their lives miserable, this particular individual also finds his life miserable. But simply because many with such handicaps find their lives miserable does not mean that all do; it seems plain that some persons with physical handicaps find their lives rich and meaningful (6).

\section{Interests and experience}

Doctors and families are often called upon to make decisions for individuals who are incapable of experience, such as anencephalics or patients in a persistent vegetative state. In these cases, decisionmakers often base their choices on the standards which we have outlined earlier: prior expressed wishes, substituted judgement, or the patient's best interests. The difficulties which we have pointed out for the first two of these standards clearly also extend to individuals incapable of experience, but the third standard, that of best interests, has difficulties with this sort of case which are unique.

Can a being that is completely incapable of experience have interests? The answer is not clear. Most commonly we use the term 'interests' in respect of persons and other beings capable of experience. A person's interests are, roughly, his 'good'. In many cases we feel that a person's interests are equivalent to the good as judged by that person. For example, when we are dealing with autonomous, mentally competent adults, we often assume that a person's interests amount to the satisfaction of his wishes or desires. Another strand in interests, however, points to the good as judged by others. This is the sense in which we might want to say that it is in a person's interests not to have his wishes satisfied - for instance, if their satisfaction would harm him in some way. A parent might invoke this sense of interests in making a decision which is contrary to his child's desires (7).

Both of these senses of interests, however, are interests for a being. That is, there is a subject of the interests. Usually we do not speak of the interests of a potato or a telephone or a brick, and presumably this is not simply because these things are incapable of judging and communicating those interests, but rather 
because they are not subjects, and thus not capable of experience. In Thomas Nagel's evocative terms (8), there is 'something that it is like' to be a conscious subject, like a person or a dolphin or a bat, but there is nothing that it is like to be a potato or a telephone or a brick. Generally we speak most comfortably of interests in reference to sentient beings which are capable of experiencing their 'good'. And if a being is incapable of any experience at all, such as anencephalics or persistent vegetative state patients, interests of this sort seem to be ruled out.

Of course, in the case of human experience, even if certain events are completely outside the bounds of our experience, we sometimes feel it is in our interests that those events not take place. For example, I might think it is in my interests not to have others spread malevolent falsehoods about me behind my back, even if the effects of this are completely outside of my experience - even if I will never know of them or be affected by them. Moreover, merely believing they are not being spread is not enough. We think it is in our interests that such falsehoods actually not be spread, whether we are aware they are being spread or not.

However, it is important to realise that even if it is not necessary for me to experience something for it to be in or contrary to my interests, this does not mean that beings without the ability to experience have interests. My interest in not having certain things outside of my experience happen stems from my desire that they not happen. My interest in not having someone spread falsehoods about me derives from the fact that I do not want anyone to spread these falsehoods. And of course, no being incapable of experience can have a desire. Thus the ability to experience seems necessary even to have an interest in something which is outside of one's experience.

On the other hand, ordinary use of the word 'interests' does extend beyond conscious beings to things incapable of experiencing their interests. For instance, some environmental philosophers would argue that non-sentient nature has interests, and that these interests give nature moral claims on us. This means that we would have obligations, say, not to destroy Brazilian rain forests even if there were no conscious beings who would ever experience their loss.

Thus it seems either that human beings incapable of experience have no interests, if to have interests something must be a subject of experience, or that if they do have interests, it is in the same sense that nonsentient nature has interests. If the former is true, then we should exclude any consideration of the interests of anencephalics or patients in a persistent vegetative state from discussion of how they ought to be treated, and concentrate instead on other considerations, such as the interests of the family, or the interests of others with a claim to medical resources, or the broader effects that might result from treating these patients in a certain way.

But if beings incapable of experience do have interests, it would seem to be in the same way that non- sentient nature has interests, and in this case it is not clear what sort of moral consideration these sorts of interests would merit. Arguments for the interests of non-sentient nature usually focus not on the moral claims of, say, an individual plant, but on a species of plant, or on a type of natural ecosystem. For this reason, it is not at all clear how interests in this sense could be applied. Thus even if we were to accord persistent vegetative state patients and anencephalics the same kinds of claims entailed by these 'nonsentient interests', this sort of interests standard will probably not be of much help in actually making decisions.

A more important question is that of whether a being incapable of experience has interests by virtue of his capacity for experience at some time in the past. Aristotle seemed to have a notion like this in mind when he argued that the happiness of the dead could be affected by the fortunes of their descendants. And some people might argue that the dead have interests in having the wishes that they expressed while alive being carried out - through a last will and testament, for example.

However, the fact that I have an interest while I am alive in having my wishes carried out at a later time, when I will be dead, does not mean that while I am dead I still have that interest. Keeping promises, respecting wishes and carrying out wills are institutions whose existence is in the interests of the living - my interests when I am alive and the interests of others when I am dead. Similar considerations apply for individuals in a persistent vegetative state. If they have interests, it will not be because of the fact that they had interests in the past.

The converse of this argument is to attribute interests to non-sentient things by virtue of their potential for experience in the future. For example, a Tennessee court recently argued along these lines for the interests of pre-sentient embryos (9). Davis v Davis concerned an infertile couple who underwent an in vitro fertilisation procedure and subsequently divorced. The first attempt at implanting an embryo had been unsuccessful, and after the couple's divorce, they had different opinions about what should be done with the remaining embryos, which were frozen. The husband did not want to become the father of these children; the wife wanted to have the embryos implanted and to carry them to term. In a decision that was later overturned, the court ruled that the embryos could be implanted because, among other things, they had interests in becoming persons.

The problems with this argument have been well rehearsed in the debates over the morality of abortion. If we say that this brute potential also entails an interest in development, then it is not clear why we should not also accord eggs and sperm similar interests, since they also have this potential. Of course, one might argue backwards, reasoning that a person has an interest in having been brought into existence: I have an interest in the embryo that was to become me becoming me, and 
the fact that I have an interest in having been brought into existence means that the embryo that was to become me had an interest in becoming me.

However, even if I could say that it is in my interests that the embryo that was to become me was allowed to develop, it does not at all follow that it was in the interests of that embryo, at that time, to be allowed to develop. Moreover, though it sounds initially plausible, it is not clear that I do in fact have an interest in having been born. Because if I have an interest in having been born, then it seems that it would be contrary to my interests not to have been born. But this, of course, is nonsense. If I had not been born, there would be no one for whose interests 'not being born' would be contrary to.

\section{Conclusion}

We have tried to point out some of the problems inherent in imagining another subjective point of view. These problems make the 'best interests standard' the most suitable way to make decisions for the severely mentally impaired, but this standard runs into difficulties of its own when it is applied to beings incapable of experience, such as anencephalics and persistent vegetative state patients. For both of these sorts of patients, those whose mental impairment makes their experience radically different from our own, and those who are incapable of any experience at all, Adam Smith had relevant observations. The former, Smith noted (with language at odds with his point), is 'altogether insensible of his own misery', and the spectator's imagination of that experience arises from his consideration of what 'he himself would feel if he was reduced to the same unhappy situation, and what is perhaps impossible, was at the same time able to regard it with his present reason and judgement' (10). For the latter, those incapable of experience, Smith's comments on imagining death are appropriate: 'It is from this very illusion of the imagination, that the foresight of our own dissolution is so terrible to us, and that the idea of those circumstances, which undoubtedly can give us no pain when we are dead, makes us miserable while we are alive' (11).

\section{Acknowledgements}

This paper was written while one of the authors (C E) was a Fellow of the University of Chicago Center for Clinical Medical Ethics, which is supported by grants from the Henry J Kaiser Foundation, the Andrew W Mellon Foundation, and the Pew Memorial Trusts. Thanks are also due Robin Downie, John Lantos and Rick Kodish for their comments on an earlier draft of this paper.

Carl Elliott, MD, PhD, is Research Fellow at the University of Otago Bioethics Research Centre. Britt Elliott, BA, teaches English at the Czechoslovakia Academy of Sciences in Trebon, Czechoslovakia.

\section{References and notes}

(1) Pascal F. Wittgenstein: a personal memoir. In: Rhees R, ed. Recollections of Wittgenstein. Oxford: Oxford University Press, 1984: 29.

(2) Geertz C. 'From the native's point of view': on the nature of anthropological understanding. In: Local knowledge. New York: Basic Books, 1983.

(3) Smith A. The theory of moral sentiments. Indianapolis: Liberty Press, 1982: 9.

(4) Mill J. Utilitarianism. Buffalo, NY: Prometheus, 1987: 20.

(5) Superintendent of Belchertown State School v Saikewicz Mass. 370 NE 2d 417 (1977).

(6) Also, as we have noted before, there is the problem of transposing the experiences of the mentally normal onto the mentally deficient. The difficulties with judging another individual's experience make it tempting to judge quality of life by non-subjective standards - a standard, say, of human flourishing, or those qualities distinctive to a human life. But these standards have difficulties of their own.

(7) Wikler D. Patient interests: clinical implications of philosophical distinctions. Fournal of the American Geriatric Society 1988; 36: 951-958.

(8) Nagel T. What is it like to be a bat? In: Nagel T. Mortal questions. Cambridge: Cambridge University Press, 1979.

(9) Davis $v$ Davis, 1990 Tenn App LEXIS 642 (13 December 1990).

(10) See reference (3): 12.

(11) See reference (3): 13. 